\title{
DISCUTINDO O CONCEITO DE CRENÇAS NA FORMAÇÃO INICIAL DO PROFESSOR DE LÍNGUAS: REFLEXÕESSOBRE UM CONCEITOEM CONSOLIDAÇÃO
}

\author{
DISCUSSINGTHE CONCEPT OF BELIEFS INTHE INITIAL FORMATIONOF \\ LANGUAGE TEACHERS: REFLECTIONS ONACONCEPTIN CONSOLIDATION
}

\author{
LEANDROTADEU ALVES DALUZ
}

\begin{abstract}
RESUMO: A formação de professores de língua estrangeira tem buscado subsídios nos estudos sobre o pensamento do professor, especialmente no que concerne às crenças na fase inicial de desenvolvimento profissional (Barcelos 2004b, 2003, 2001, Johnson 1999 e 1994, Gimenez 1994, Pajares 1992). Este trabalho tem como objetivo apresentar e discutir o conceito de crenças que, segundo Pajares (1992) é um conceito bastante complexo e de difícil definição. Além disso, este trabalho discute ainda a importância de se estudar as crenças na formação do professor de línguas, especificamente na formação inicial que acontece, tradicionalmente, no curso de Letras.
\end{abstract}

Palavras-chave: formação; crenças; conceito

ABSTRACT: English language teachers' education has benefited from insights of research in teacher's thinking, especially in studies about beliefs at the initial phase of professional development (Barcelos 2004b, 2003, 2001, Johnson 1999 e 1994, Gimenez 1994, Pajares 1992). This study aims at presenting and discussing the concept of beliefs, which, according to Pajares (1992) is very complex and difficult to define. In addition, this work further discusses the importance of studying beliefs in languages teacher education, especially at the pre-service stage, which, traditionally, takes place in the Letras course.

Key-words: teacher's education; beliefs; concept

\section{INTRODUÇÃO}

Este trabalho busca tratar da formação inicial de professores de Inglês e se insere no paradigma de investigação do pensamento do professor, que, segundo Dias (2002, p. 14),

* Mestre em Estudos da Linguagem pela Universidade Estadual de Londrina (UEL), Departamento de Línguas Estrangeiras Modernas (LEM), Londrina, PR 
LUZ - Discutindo o conceito de crenças na formação inicial do professor de línguas...

indaga "sobre os processos pelos quais os professores geram conhecimento, além dos tipos de conhecimentos que estes profissionais adquirem". Tem como objetivo discutir o conceito de crenças e suas implicações para o processo de formação inicial do professor de línguas.

Centrar a pesquisa no processo de formação inicial do professor de línguas significa voltar os olhos aos cursos de graduação em Letras (classicamente o curso que forma professor de línguas). Diversas têm sido as discussões a respeito dos problemas e sobre o destino dos cursos de Letras no Brasil (Freudenberger e Rottava 2004, Xavier e Gil 2004, Gimenez 2004, Dutra 2003, Aaraujo, 2003). Sabe-se, por exemplo, que os quatro anos destinados a formar um professor que lide com as questões da linguagem em língua materna e em língua estrangeira não são suficientes (Oliveira e Paiva, 2003). Sabe-se que um currículo que privilegia a questão da metalinguagem não forma um professor crítico-reflexivo capaz de promover sua própria formação permanente (Consolo, 2003) - aspecto essencial ao bom desempenho de qualquer profissional.

Não basta mais, diante dos avanços da sociedade, pensar num professor que sabe o conteúdo e algumas técnicas de transmissão de conhecimento. Professor hoje, mais que nunca, como aponta Demo (2004), não é aquele que dá aula, simplesmente, mas é aquele que cuida da aprendizagem sua e do seu aluno. O bom professor hoje não é quem ensina bem somente, mas aquele que aprende bem. E aprende bem para transformar, para acrescentar, para reconstruir o conhecimento e não mais reproduzir.

Vários estudos têm demonstrado que, para o professor lidar com tais mudanças, é essencial o papel da pesquisa, bem como da reflexão crítica em sua formação inicial e em sua prática docente (Dutra e Mello 2004, Demo 2004, Jorge 2003, Celani 2003, Pimenta e Ghedin 2002, Kleiman 2001, Perrenoud 2001, Schön 2000, Almeida Filho 1999, Gimenez 1999, Nóvoa 1997).

Reflexão engajada é aquela que promove a transformação. A este respeito, vale observar o que afirma Moita Lopes (2003, p. 31)

Se a educação quer fazer pensar ou talvez pensar para transformar o mundo de modo a se poder agir politicamente, é crucial que todo professor - e, na verdade, todo cidadão - entenda o mundo em que vive e, portanto, os processos sociais, políticos, econômicos, tecnológicos e culturais que estamos vivenciando. Não se pode transformar o que não se entende. Sem a compreensão do que se vive, não há vida política.

A respeito da relação entre reflexão crítica na formação de professores e o estudo das crenças destes professores, Barcelos (2004a, p. 145) afirma que

O entendimento destas crenças faz parte de formar professores críticos, reflexivos e questionadores do mundo a sua volta (não somente da sua prática). Nós precisamos aprender a trabalhar com crenças em sala, já que ter consciência sobre nossas crenças e ser capazes de falar sobre elas é um primeiro passo para professores e alunos reflexivos.

Acredito, assim, na importância de se estudar as crenças de futuros professores de Inglês, principalmente pelo fato de que nossas crenças permeiam nossa forma de pensar, de 
construir conhecimento e de agir como pessoa e como profissional (Farrell e Particia 2005, Silva 2004, Barcelos 2004b, 2003a, 2003b, Massarollo e Fortkamp 2002, Brownlee et al 2001, Johnson 1999 e 1994, Maláter 1998, Gimenes 1994, Pajares 1992).

Se as crenças estão presentes nas formas de pensar e de agir como pessoa e como profissional e se formar um professor significa mais do que transmitir conhecimentos prontos, então o conhecimento e o entendimento das crenças são fundamentais para que este professor não se torne um repetidor de modelos, mas sim, um conhecedor de padrões diversos e consciente para fazer escolhas entre eles.

Conhecer crenças permite que o lado mais humano do profissional e de sua formação se faça presente. Significa resgatar uma história de vida, uma história de contato intenso com a escola que se inicia muito antes de qualquer pensamento de se tornar professor (Lortie, 1975).

Diversos estudos têm focado nas crenças de professores e seu papel na formação.

Madeira (2005b), por exemplo, buscou traçar um panorama das pesquisas, conceitos e metodologias envolvidos nos estudos das crenças de professores e alunos. O autor também sugere um histórico dos estudos sobre crenças, seguido pela discussão sobre seu conceito. Madeira situa a importância de se estudar as crenças de alunos e professores em contextos de ensino/aprendizagem de línguas no fato também atestado por outros pesquisadores de que as crenças influenciam diretamente as estratégias de ensino e de aprendizagem de uma língua.

O pesquisador conclui seu trabalho expondo que, apesar das dificuldades que envolvem a delimitação e interpretação das crenças no ensino/aprendizagem de línguas, este é um tipo de conhecimento que precisa ser investigado e entendido para que se possa formar professores mais críticos, conscientes e preparados enfim, para os desafios da sala de aula.

Freudenberger e Rottava (2004) buscaram identificar as crenças de ensinar de professores de Inglês em formação inicial. O objetivo central era comparar as crenças dos alunos do segundo semestre com aquelas dos alunos do sexto semestre de um curso de graduação em Letras buscando observar o impacto da graduação sobre as crenças desses futuros professores. As pesquisadoras coletaram dados por meio de uma entrevista com 08 estudantes de uma universidade do Sul do Brasil.

$\mathrm{O}$ estudo apontou diferenças entre as crenças dos alunos do segundo e do sexto semestre em relação aos seguintes aspectos: 1) crenças com relação às habilidades mais importantes para o ensino de LE; 2) crenças em relação à gramática e seu uso; 3) crenças a respeito do que seja ensinar e 4) crenças sobre o papel do professor no ensino.

Vieira-Abrahão (2004) apresenta alguns resultados de um trabalho a respeito de crenças sobre linguagem, ensinar e aprender línguas que alunos-professores trazem ao curso de graduação. Sua pesquisa conta com seis informantes, sendo cinco futuros professores de Inglês e um futuro professor de Espanhol. A maioria de seus informantes vem da escola pública e todos estudaram a língua que pretendem ensinar fora da escola regular. A pesquisadora fez uso de vários instrumentos de coleta de dados: autobiografias, sessões de "histórias de vida", questionário, inventário de crenças e relatório do aluno-professor. 
LUZ - Discutindo o conceito de crenças na formação inicial do professor de línguas...

Os resultados foram agrupados em sete categorias, sendo elas: concepções de linguagem; concepções de ensino; concepções de aprendizagem; papéis de professores e alunos; fatores que afetam a aprendizagem da língua estrangeira; conceito de erro, correção e avaliação na sala de aula de LE e o livro didático no ensino de LE.

A análise demonstrou que os participantes trazem boas e más lembranças de seu contato com o ensino fundamental e médio, e que estas experiências influem na sua forma de pensar e agir no curso de formação. Este estudo demonstrou também a importância de se criar oportunidades para que os alunos-professores em processo de formação inicial tomem consciência de suas crenças e que possam sobre elas refletir de forma crítica e, se necessário for, modificá-las.

\section{CRENÇAS NA FORMAÇÃO INICIAL DO PROFESSOR DE LÍNGUAS}

Atualmente, as questões relacionadas à formação de professores de línguas têm se tornado foco de diversas pesquisas em LA, em trabalhos publicados em periódicos, discussões em congressos ou temas de dissertações e teses (Gil 2005, Gimenez 2005, Leffa 2005, Barcelos 2004a e 2004b, Vieira-Abrahão 2004, Freire e Lessa 2003, Celani 2003, Barbara e Ramos 2003, Bertoldo 2003, Gimenez 2002, Leffa 2001, dentre outros).

Algumas questões têm recebido mais atenção, como por exemplo, a construção da identidade do professor (Harkot-de-la-Taille 2003, Ghirardi, 2003), a reflexão crítica na formação de professores de línguas (Gimenez, Arruda e Luvuzari 2004, Dutra e Mello 2004, Jorge 2003, Zyingier e Liberali 2003, Pinheiro 2003, Liberali, Magalhães e Souza Romero 2003), a relação teoria e prática na formação inicial (Castro 2003, Vieira-Abrahão 2002) entre outras.

A investigação sobre as crenças dos professores de Inglês também figura entre as preocupações atuais das pesquisas sobre formação de professores (Gil et al. 2005; Kudiess 2005, Madeira 2005a e 2005b, D'Ely e Gil 2005a e 2005b, Lima 2005, Vechetini 2005, Basturkmen et al 2004, Vieira-Abrahão 2004, Freudenberger e Rottava 2004, Silva 2004, Barcelos 2004a, 2004b e 2003, Araujo 2003, Massarollo e Fortkamp 2002).

As diversas pesquisas sobre crenças indicam um traço comum: o importante papel que elas exercem no processo de formação do professor. As crenças que os alunosprofessores trazem consigo quando iniciam seu processo de formação e que o acompanham durante todo este processo, que, como já se sabe, não se limita à graduação, interferem diretamente na forma como o professor constrói seu conhecimento e sua ação pedagógica. Por isso, é unânime, entre os pesquisadores da área, a necessidade de se identificar e entender as crenças de alunos-professores e suas implicações para o seu processo de formação, conforme salienta Barcelos (2001, p. 73)

As crenças influenciam como as pessoas organizam e definem suas tarefas. Em outras palavras, elas são fortes indicadores de como as pessoas agem. Na literatura em LA, a relação entre crenças e ações refere-se à maneira como as crenças podem influenciar a abordagem dos alunos em relação à aprendizagem. 
A pesquisa sobre crenças ainda é bastante recente (meados dos anos 80 no exterior e 90 no Brasil) e surgiu de uma mudança na LA do estudo do produto para o estudo do processo. O próprio conceito de crenças parece estar ainda em processo de consolidação.

\section{O CONCEITO DE CRENÇAS}

A definição do conceito de crenças é bastante complexa (Pajares, 1992). De modo geral, elas podem ser entendidas como um conjunto de significações provenientes das interpretações de nossas experiências na vida. É como se vivendo, experienciando e interpretando as experiências, fôssemos desenvolvendo uma teoria de como a vida é ou como deveria ser.

Alguns estudos sobre crenças tendem a entendê-las e defini-las de um ponto de vista puramente cognitivo (Brownlee et al, 1998). Este não é o caso deste trabalho, entretanto. Adotando Barcelos (2004a, 2004b, 2003a, 2003b, 2001) como principal referencial a respeito de crenças, esta pesquisa entende crenças a partir de uma visão sociológica, o que, alguns teóricos têm chamado de representações (Castro 2004, Celani e Magalhães 2000).

De acordo com Castro (2004, p. 41) "as representações são as significações construídas pelos indivíduos, como resultado de sua participação nas atividades das diversas formações sociais às quais pertencem".

Castro (2004, p. 42) afirma ainda que

As representações sobre ensinar e aprender dos futuros professores de Inglês são amplamente construídas e reconstruídas como resultado de sua participação nas atividades dos contextos escolares nos quais tem lugar sua formação lingüístico-textual, ou seja, nas aulas de língua inglesa dos cursos de Letras.

As crenças e/ou as representações sociais tratam, enfim, das significações que são adquiridas ao longo de uma vida em contato com outras vidas, com o meio e com as situações. O indivíduo vai estabelecendo relações e vai construindo um arcabouço de significações a partir de tais relações. Este arcabouço de significações está sendo chamado, neste trabalho, de crenças.

Barcelos (2003a) apresenta um quadro de nomenclaturas e definições para o termo "crenças" no ensino-aprendizagem de línguas. Algumas das definições trazidas para as várias denominações possíveis (idéias, concepções, conhecimento intuitivo etc) são pouco esclarecedoras.

Contudo, considero importante salientar os outros termos apresentados como sinônimos de crenças e as razoes pelas quais os considero diferentes.

Não é possível, por exemplo, admitir que os termos crença e opinião sejam sinônimos como sugere Wenden (1986, p. 05 apud: Barcelos op.cit) em sua definição. As opiniões são descompromissadas e facilmente mutáveis, ao contrário das crenças, que, exatamente por sua origem na experiência, tendem mais à estabilidade, à consolidação do que à mudança. Quando se crê em algo se crê até que surja um argumento forte o suficiente para desestabilizar 
LUZ - Discutindo o conceito de crenças na formação inicial do professor de línguas...

esta crença. Uma opinião, por outro lado, pode mudar a qualquer momento sem motivo aparente.

Finalmente, as opiniões são superficiais, por isso mais facilmente identificáveis, ao passo que as crenças são, na maioria das vezes, implícitas e até mesmo desconhecidas de quem as possui. A maioria de nós, se questionados sobre nossa opinião a respeito do racismo vamos rapidamente dizer que somos contra, que, na nossa opinião, nem sequer existe racismo no Brasil. Se observarmos nossas ações com cuidado, entretanto, vamos descobrir que guardamos crenças bastante racistas, as quais negamos ou nem sequer conhecemos.

É importante entender as características das crenças para que se possa enfim, entender, em que medida elas se diferem de simples opiniões.

Massarollo e Fortkamp (2002) apresentam algumas das características das crenças, afirmando que elas:

(1) influenciam nossas ações e são por elas influenciadas; (2) pertencem a um domínio específico e organizam-se em estruturas; (3) têm sua alteração influenciada pelo tempo que pertencem ao sistema de crenças do indivíduo; (4) são transmitidas culturalmente e construídas socialmente; (5) fazem parte da nossa capacidade de compreender o mundo social e de enfrentar problemas; (6) devem ser tomadas e interpretadas a partir de afirmações, intenções e ações; (7) são dinâmicas.

Um aspecto relevante do estudo das crenças trata da sua distinção em relação ao conhecimento. Brownlee et al (1998, p. 107) afirmam que "as crenças podem ser tomadas como construções subjetivas que influenciam o comportamento, ao passo que o conhecimento pode ser mais comumente entendido como verdades objetivas".

Pajares (1992) propõe uma distinção entre o que ele chama de sistema de crenças e sistema de conhecimento. Segundo o autor (Pajares, 1992, p. 314) "crenças, atitudes e valores formam um sistema individual de crenças". Apesar de individual, vale lembrar que este sistema se forma ao longo da vida e das experiências sociais de cada um. Só é individual no sentido em que pertence a cada indivíduo particularmente, que cada indivíduo pode interpretar a realidade que o cerca e suas experiências de contato com esta realidade de forma distinta e única.

O sistema de conhecimento, por sua vez, não permite a liberdade de interpretações, tampouco a individualidade de que fala Pajares (op. cit.). Dentro do sistema de conhecimento as verdades existem ou não e; se existem, são coletivas, isto é, aceitas como sendo verdadeiras por um grupo ou uma comunidade.

Vale trazer as contribuições de Abelson (1979, p. 359), quando o autor propõe a seguinte caracterização para o sistema de crenças ${ }^{1}$ :

a) Pressuposição existencial ou não existência de fatos ou situações;

\footnotetext{
${ }^{1}$ Tradução minha.
} 
b) Alternatividade: as crenças dizem respeito a alternativas para práticas conhecidas das quais a pessoa pode ainda não ter experiência direta, ou seja, uma crença pode existir independentemente de ter sido experimentada;

c) Aspectos afetivos e avaliadores: as crenças se baseiam fortemente em componentes afetivos e de avaliações subjetivas;

d) Armazenamento episódico: as crenças são armazenadas como episódios oriundos da experiência pessoal, e não em redes semânticas;

e) Não-unanimidade: as afirmações que compõem as crenças são reconhecidas como questionáveis dentro de um grupo ou comunidade;

f) Limites não demarcados: as crenças têm ligações pouco definidas com eventos, situações e sistemas de conhecimento;

g) Variabilidade: as crenças podem ser sustentadas com graus de certeza variados.

Para Pajares (1992) este sistema de crenças é construído por um processo de aculturação e se trata de uma construção social. Como consequiência deste processo, o autor (1992, p. 317) afirma que

Experiências precoces influenciam fortemente os julgamentos finais, que se tornam teorias (crenças) altamente resistentes à mudança. Os resultados são perseverantes fenômenos de resistência da teoria. Devido a esse fenômeno, quanto mais precocemente uma crença for incorporada à estrutura de crenças, mais difícil é para alterá-la, porque essas crenças afetam subseqüentemente a percepção e influenciam fortemente o processamento de uma nova informação.

As crenças parecem funcionar como um filtro de informações, isto é, todo novo conhecimento proposto vai passar antes pelo filtro daquilo que eu acredito, daquilo que é o resultado da minha interpretação de tudo que eu tenho vivido. Como a escola entra muito cedo em nossas vidas, nossas crenças envolvendo a sala de aula e o professor estão muito cristalizadas.

Pajares (1992, p. 324, 325 e 326) apresenta uma lista de aspectos a serem considerados em relação ao estudo das crenças, aspectos estes que gostaria de apresentar neste momento, apesar da longa citação, exatamente por entender que eles sintetizam o que venho discutindo até agora ${ }^{2}$ :

1.As crenças são formadas precocemente e tendem a se autoperpetuar, persistindo mesmo contra contradições causadas pelo raciocínio, pelo tempo, pela educação ou pela experiência;

2. Os indivíduos desenvolvem um sistema que armazena todas as crenças adquiridas por meio de um processo de transmissão cultural;

3.O sistema de crenças tem uma função adaptativa no sentido de ajudar os indivíduos a definir e entender o mundo e a si mesmos;

\footnotetext{
${ }^{2}$ Tradução minha.
} 
LUZ - Discutindo o conceito de crenças na formação inicial do professor de línguas...

4.O conhecimento e as crenças são intimamente entrelaçados, mas a natureza afetiva, avaliativa e episódica das crenças faz com que elas funcionem como um filtro por meio do qual novos fenômenos são interpretados;

5.Os pensamentos podem ser precursores ou criadores de crenças, mas o efeito de filtragem das crenças em última instância molda, redefine, distorce ou formata pensamentos subseqüentes bem como o processamento de informação;

6.Crenças epistemológicas exercem um papel fundamental na interpretação do conhecimento e no monitoramento cognitivo;

7.As crenças são priorizadas de acordo com suas conexões e relações com outras crenças e outras estruturas afetivas e/ou cognitivas. Aparentes inconsistências podem ser explicadas explorando as conexões funcionais e a centralidade das crenças;

8.As subestruturas das crenças, tais como as crenças educacionais, devem ser entendidas em termos de suas conexões, não somente uma em relação à outra, mas também em relação a outras crenças, talvez mais centrais no sistema. Psicólogos geralmente se referem a estas subestruturas como atitudes e valores;

9.Exatamente pela sua natureza e origem, algumas crenças são mais resistentes a mudanças do que outras;

10. Quanto mais cedo uma crença é incorporada à estrutura de crenças, mais difícil é alterá-la. Crenças adquiridas recentemente são mais vulneráveis a mudanças.

11. A mudança nas crenças em adultos é um fenômeno relativamente raro. A causa mais comum de tal mudança é a conversão de uma autoridade para outra. Os indivíduos tendem a confiar em crenças baseadas em conhecimentos incorretos ou incompletos, mesmo depois que explicações cientificamente corretas lhes são apresentadas.

12. As crenças são instrumentais em definir tarefas e selecionar as ferramentas cognitivas com as quais se interpreta, planeja e se age quanto a tais tarefas; por isso elas exercem um papel crucial na definição do comportamento e na organização do conhecimento e da informação;

13. As crenças influenciam fortemente a percepção, mas elas podem ser um guia incerto sobre a natureza da realidade;

14. As crenças dos indivíduos influenciam fortemente seu comportamento;

15. As crenças devem ser inferidas, e esta inferência deve levar em consideração a congruência entre as declarações de crenças dos indivíduos, a intencionalidade de se comportar de uma determinada maneira e o comportamento relacionado à crença em questão;

16. As crenças sobre ensino já estão bem consolidadas no momento em que um estudante chega à Universidade.

Finalmente, a respeito da formação deste sistema de crenças de professores, Massarollo e Fortkamp (2002, p.08) afirmam que

Como apontado por vários pesquisadores (Kindsvatter, Willen, and Ishler, 1988; Richards, 1994), o sistema de crenças de professores é construído de maneira gradual ao longo do tempo e é derivado de diferentes situações tais como: (1) sua própria experiência como aprendizes de língua; (2) experiências quanto às estratégias de ensino que proporcionam 
Trab.Ling.Aplic., Campinas, 46(2) - Jul./Dez. 2007

melhores resultados; (3) práticas de ensino preferidas ou determinadas pela instituição; (4) preferências pessoais por determinado modelo de ensino; (5) princípios baseados em programas instrucionais ou pesquisas; (6) princípios derivados de um determinado método ou abordagem de ensino.

Pensar o processo de consolidação ou de questionamento das crenças deve fazer parte do processo de formação do professor, tanto no âmbito inicial quanto continuado. Esta é exatamente a discussão da próxima subseção.

\section{CRENÇASE FILOSOFIA}

Grandes filósofos também se preocuparam com a definição de crenças. O Dicionário de filosofia elaborado por Soares (1952), por exemplo, traz importantes contribuições a esta discussão. Primeiramente, o dicionário traz os significados do termo crenças para a psicologia, que trata crenças como uma adesão a um julgamento com atitude de certeza. Atitude de certeza, segundo o dicionário, pode ser decorrente tanto de uma razão teórica, demonstrável, quanto de uma fonte não totalmente demonstrável. É possível perceber já a distinção entre um tipo de conhecimento que é teórico e um tipo de conhecimento advindo da experiência de contato com o mundo e com as outras pessoas.

Alguns outros aspectos são apresentados no dicionário de Soares, como "crença ardente" que trata do transbordamento da convicção, podendo existir em caráter episódico, mais nos domínios da política ou em caráter permanente na fé; não se tratando, entretanto, de fanatismo, que é uma paixão fechada em si mesma. "Crença coletiva" é aquela partilhada por um grupo social qualquer, se sustenta no conformismo e na imitação. Bastante comum entre os adolescentes, por exemplo, quando o grupo acredita em algo, para fazer parte do grupo, o adolescente acaba adotando esta crença como sua também. Na religião, são as crenças coletivas que criam os símbolos.

Para "crença e dúvida", o autor afirma que "a dúvida nasce do conflito do espírito com o julgamento; a crença, da adesão do espírito ao julgamento" (Soares, 1952, P. 263). A crença nasce, assim, quando a pessoa sustenta seu julgamento com convicção, quando acredita a ponto de não restar nenhuma dúvida.

O Dizionario di Filosofia (1970), traduzido por Alfredo Bosi, apresenta o pensamento de alguns filósofos sobre este tópico. Platão, por exemplo, entendia crenças como referente à parte sensível, ligada à realidade, diferenciando crenças de conjecturas, ligadas às sombras ou imagens. Aristóteles, por sua vez, aproxima crenças de opinião, segundo o filósofo "não é possível que quem tenha opinião não creia no que pensa" (Bosi, 203). Refletindo sobre esta máxima de Aristóteles, observo que, para o filósofo, a opinião é o pensamento simplesmente, ao passo que a crença me soa como a validação deste pensamento. Se eu penso, eu tenho opinião e se eu creio na minha opinião, então, tenho uma crença.

Locke, na filosofia moderna, distingue o conhecimento certo do provável e atribui vários níveis ao provável, dentre os quais, a crença é o mais alto. Kant reconheceu três diferentes graus de crenças: a opinião, a fé e a ciência. Para o autor, opinião é uma crença 
LUZ - Discutindo o conceito de crenças na formação inicial do professor de línguas...

insuficiente tanto subjetiva quanto objetivamente, féé uma crença insuficiente apenas objetivamente e a ciência é uma crença suficiente tanto do ponto de vista objetivo quanto do subjetivo.

A distinção entre opinião, fé e ciência estabelecida por Kant parece esclarecer algumas questões em relação ao estudo das crenças. Na verdade, para o autor, tudo são crenças, com maior ou menor adesão ou profundidade. Uma teoria científica só é válida se acreditada por uma comunidade científica e, para tal, há que se fazer verdade objetiva e subjetivamente. A fé, por outro lado, não necessita de provas para que exista, basta satisfazer ao subjetivo de cada um e a opinião, por sua vez, não representa um conhecimento ou envolvimento, é tão somente a expressão de um pensamento, de um julgamento de valor.

Talvez pareça contraditório a alguém que busca fazer ciência afirmar que a ciência também é uma crença, mas, é preciso entender bem a questão do objetivo e do subjetivo na ciência. O cientista precisa crer no que pesquisa e precisa fazer crer também o grupo ao qual pertence, se ele apenas convence a si mesmo, terá fé e não ciência, se não convence nem a si mesmo, terá, então, apenas uma opinião.

Para ser ciência, a crença em algo precisa ser suficientemente forte e dotada de argumentos tais que possa ser mais que uma crença pessoal e seja aceita como verdade ainda que limitada. A ciência já desmentiu grandes crenças populares e também já foi inúmeras vezes desmentida. Não há, portanto, uma verdade científica, há um conhecimento científico compartilhado por um grupo e suficientemente forte em sua explicação de um fenômeno para que perdure enquanto não se prova uma outra verdade.

A busca por esta credibilidade é que justifica fazer ciência como a fazemos, por isso estou agora aqui redigindo um relatório que visa a tornar público e crível a um grupo de cientistas aquilo em que tenho fé e acredito.

Peirce, estudando crenças, concentra-se na influência que ela exerce sobre a ação, constituindo o que o filósofo chamou de hábito e que serviu de fundamento ao pragmatismo. Peirce caracterizou crenças da seguinte forma: " 1 e ela é algo de que comamos consciência; $2^{\circ}$ aquieta a irritação da dúvida; $3^{\circ}$ implica o estabelecer-se de uma regra de ação, isto é, de um hábito" (Bosi, 1970, p. 204). Os princípios de Peirce, principalmente em relação ao estabelecimento de um hábito é o que justifica as pesquisas sobre crenças no ensinoaprendizagem de língua e na formação do professor ainda hoje. É possível, por meio do conhecimento e entendimento das crenças, conhecer e entender os hábitos dos professores e vice-versa, por meio da observação das ações em sala de aula, é possível diagnosticar a presença de determinadas crenças.

\section{PESQUISAS SOBRE CRENÇAS: PARADIGMAS E METODOLOGIAS}

A investigação sobre crenças apresenta momentos distintos, com objetivos e metodologias específicas.

Segundo Barcelos (2004a, 2001), a primeira abordagem de investigação das crenças foi chamada de normativa. Os estudos desta abordagem sugerem que as crenças são indicadores dos comportamentos futuros dos alunos. 
Dentro da primeira abordagem, foram utilizados, predominantemente, questionários fechados como forma de coleta de dados. Durante este período, as crenças eram vistas como "noções preconcebidas, mitos ou concepções equivocadas" (Barcelos e Kalaja, 2003, p. 11).

Barcelos (2001, p. 77) sintetiza a abordagem normativa afirmando que

Em resumo, na abordagem normativa, as crenças sobre aprendizagem de línguas são definidas como opiniões que os alunos possuem sobre aprendizagem de línguas que influenciam sua abordagem ou sua prontidão para o ensino autônomo.

A abordagem metacognitiva, por sua vez, aproxima a pesquisa de crenças com as pesquisas sobre estratégias de aprendizagem, adota-se, então, uma perspectiva de aluno "construído ideologicamente" (Barcelos, 2004a, p. 136). Os estudos incluídos nesta abordagem definem crenças como conhecimento metacognitivo, daí o nome da abordagem. Os estudos utilizam basicamente entrevistas semi-estruturadas e auto-relatos.

O pressuposto implícito é de que o conhecimento metacognitivo dos alunos os ajudará a refletir sobre o que fazem e a desenvolver sua aprendizagem. Existem poucos estudos que se encaixam nesta abordagem e eles se baseiam nas teorias cognitivistas e em sua relação com a aprendizagem (Barcelos, 2001).

O contexto, assim como outros aspectos (identidade, metáforas, uso de diferentes teorias sócio-histórico-culturais), surgem num terceiro momento, chamado de abordagem contextual, caracterizado por uma "maior pluralidade de metodologias de coleta de dados e de percepções diferentes sobre como fazer pesquisa a respeito de crenças" (Barcelos, 2004a, p. 137).

Os estudos que se encaixam abordagem contextual fazem uso de observações em salas de aula e de análise do contexto, tais estudos entendem as crenças como específicas de um determinado contexto.

A abordagem contextual se difere das demais por apresentar uma definição de crenças mais ampla e por considerar o contexto como elemento chave na investigação e compreensão das crenças. Apesar de apresentar algumas vantagens em relação às outras duas abordagens, principalmente em relação à riqueza de detalhes, esta abordagem é mais adequada a investigações com um número pequeno de participantes.

Observando as características das três abordagens acima descritas, foi possível perceber que todas elas apresentam pontos positivos e negativos. Não é possível afirmar que existe uma abordagem correta para se investigar as crenças. Sem dúvida, o acesso às crenças de alunos e professores representa por si só um objeto de estudo a ser desenvolvido.

\section{CONCLUSÃO: FORMAÇÃO INICIAL, DESAFIANDO CRENÇAS}

É importante pensar numa forma de investigar as crenças durante o processo de formação inicial para que o aluno possa sobre elas refletir e perceber enfim, que suas teorias pessoais são somente crenças e não verdades absolutas e que, ainda que elas possam the 
LUZ - Discutindo o conceito de crenças na formação inicial do professor de línguas...

parecer altamente significativas e coerentes, elas são também altamente subjetivas e não representam a realidade, mas apenas a interpretação da realidade.

Por sua formação desde o início da vida escolar, as crenças sobre educação estão tão solidificadas (Pajares, 1992) que, a menos que a formação inicial represente um impacto realmente significativo, o aluno vai sair da graduação e reproduzir em sala de aula atitudes que refletem mais suas crenças do que seu conhecimento teórico (Cole, 1990).

A grande questão é saber o grau de impacto do processo de formação inicial do professor sobre o seu sistema de crenças e o problema, muitas vezes, é encontrar no curso de formação inicial, professores formadores que repetem modelos de aula que só reforçam certas crenças. De nada adianta a teoria que o professor ensina postular que, na sala de aula deve haver interação e construção de conhecimento, se o professor ensina isso sem promover nenhuma interação, transmitindo e não construindo conhecimento. A ação e a palavra precisam ambas reforçar atitudes que provoquem o questionamento e não que confirmem aquilo que o aluno já sabe ou acredita saber.

Para Pajares (1992, p. 321) "As crenças são dificilmente substituídas a menos que elas sejam comprovadas como insatisfatórias, e elas dificilmente se tornam insatisfatórias senão forem desafiadas". Penso num curso de formação inicial que exerça exatamente o papel de desafiar crenças, para isto é preciso que elas sejam conhecidas para serem questionadas e, quando necessário, substituídas por um conhecimento elaborado por meio da pesquisa e da reflexão.

Acredito, assim, no desafio da pesquisa e da reflexão crítica (Brownlee et al, 1998) como garantia de questionamento e redimensionamento de crenças e atitudes. É preciso, pois, pensar num processo de formação inicial que, ao invés de apresentar respostas prontas, pesquisas acabadas, conhecimento construído, o que só reforça a crença de que ensino é transmissão de conhecimento pronto; apresente dúvidas, questionamentos, propostas de elaboração de pesquisas, que desafie, enfim, desestabilizando o que o aluno acredita, não para menosprezar seus conhecimentos prévios, mas para fazer com que ele olhe para estes conhecimentos com um olhar reflexivo e (re) construtivo.

O impacto da graduação, assim, a meu ver, se dá na percepção da existência de um conhecimento pessoal, fundado na experiência e de um conhecimento teórico, advindo da pesquisa científica e de que ambos estão sujeitos a questionamentos e transformações. É preciso reconhecer que não existem verdades prontas e absolutas; que as coisas não são, as coisas estão sendo e que, portanto, o saber se faz por meio de um processo que é dinâmico e que é constante, em que as verdades só duram enquanto puderem se manter como verdades. Não basta que eu acredite nelas para que elas permaneçam, é preciso que elas se mostrem verdadeiras diante de questionamentos e de outras verdades.

\section{REFERÊNCIASBIBLIOGRÁFICAS}

ABELSON, R. P. (1979). Differences between belief and knowledge systems. Cognitive Science, vol. 3, pp. 355-366. 
ALMEIDA FILHO, J. C. (1999). O professor de língua estrangeira em formação. São Paulo: Pontes.

ARAÚJO, A. D. (2003). Crenças e concepções do professor-educador sobre a formação do professor de língua estrangeira in: GIMENEZ, T. (org.) Ensinando e aprendendo inglês na universidade: formação de professores em tempos de mudança. Londrina: ABRAPUI.

BARBARA, L. e RAMOS, R. C. (2003). Reflexão e ações no ensino-aprendizagem de línguas (orgs). Campinas, SP: Mercado de Letras.

BARCELOS, A. M. F. (2004a). Crenças sobre aprendizagem de línguas, Lingüística Aplicada e ensino de línguas in: Linguagem Ensino, Vol. 07, no. 1. pp. 123-156 Pelotas: Educat.

(2004b). Ser professor de Inglês: crenças, expectativas e dificuldades dos alunos de Letras in: ABRAHÃO. Prática de ensino de língua estrangeira: experiências e reflexões. Campinas, SP: Pontes Editora.

BARCELOS, A. M. F. e KALAJA, P. (2003a). Beliefs about SLA: new research approaches. Dordrecht, The Netherlands: Kluwer academic publishers.

(2003). Beliefs about SLA: new research approaches. Dordrecht, The Netherlands: Kluwer academic publishers.

BARCELOS, A. M. (2003). As crenças de professores a respeito das crenças sobre aprendizagem de línguas de seus alunos in: GIMENEZ, T. (org.). Ensinando e aprendendo inglês na universidade: formação de professores em tempos de mudança. Londrina: ABRAPUI.

. (2001). Metodologia de pesquisa das crenças sobre aprendizagem de línguas: Estado da arte in: Revista Brasileira de Lingüística Aplicada, v. 1, n.1, pp. 71-92.

BASTURKMEN, H., LOWEN, S. E ELLIS R. (2004). Teachers' stated beliefs about incidental focus on form and their classroom practices in: Applied Linguistics, vol. 25, $\mathrm{n}^{\circ}$ 02, pp. 243-272.

BERTOLDO, E. S. (2003). Lingüística aplicada e formação de professores de língua estrangeira in: FREITAS, A. C. e CASTRO M. F. F. Guilherme (org.). Língua e Literatura: ensino e pesquisa. São Paulo: Contexto, 2003.

BOSI, A. (trad.) (1970). Dizionário de Filosofia. São Paulo: Ed. Mestre jou.

BROWNLEE, J. NOLA P. \& BOULTON-LEWIS G. (2001). Changing epistemological beliefs in preservice teacher education students in: Teaching in Higher Education. Vol. 6, $\mathrm{n}^{\circ} 2$.

BROWNLEE, J.; DART, B.; BOULTON-LEWIS, G \& McCRINDLE, A. (1998). The integration of preservice teachers' naïve and informed beliefs about learning and teaching.in: Asia-Pacific journal of teacher education, Vol. 26, $\mathrm{n}^{\mathrm{o}} 2$.

CASTRO, S. T. R. (2003). Teoria e prática no processo de reculturação de professores de Inglês in: CELANI (org.). Professores e formadores em mudança: relato de um processo de reflexão e transformação da prática docente. Campinas, SP: Mercado de Letras.

CELANI, M.A.A. (org.). (2003). Professores e formadores em mudança: relato de um processo de reflexão e transformação da prática docente. Campinas, SP: Mercado de Letras.

CELANI, M. A. A. e MAGALHÃES, M. C. C. (2000). Representações de professores de inglês como língua estrangeira sobre suas identidades profissionais: Uma proposta de reconstrução in: MOITA LOPES, L. P. e BASTOS, L. C. (orgs.). Identidades: Recortes multi e interdisciplinares. Campinas, SP: Mercado de Letras. 
LUZ - Discutindo o conceito de crenças na formação inicial do professor de línguas...

CONSOLO, D. A. Formação de professores de línguas: reflexão sobre uma (re)definição de posturas pedagógicas no cenário brasileiro.

CASTRO, M. F. GUILHERME (org.). (2003). Língua e literatura: ensino e pesquisa. São Paulo: Contexto.

COLE, A. L. (1990). Personal theories of teaching: development in the formative years in: The Alberta Journal of Educational Research. Vol. XXXVI, nº 3, pp. 203-222.

D'ELY, R. C. S. F. \& GIL, G. (2005a). In search for an equilibrium: a teacher's view on her practice in: TOMITCH, L. M. B. et al (orgs.) A interculturalidade no ensino de Inglês. Florianópolis: UFSC. . (2005b). Investigating the impact of na ELT methodology course on student-teachers' beliefs, attitudes and teaching practices in: The ESPecialist, vol. 26, no.1, pp. 23-52.

DEMO, P. (2004). Professor do futuro e reconstrução do conhecimento. Petrópolis - RJ: Editora Vozes.

DIAS, L. C. F. (2002). Tornando-se professor: as vozes que participam da formação pessoal/profissional in: Linguagem \& Ensino, Vol. 5, nº. 1, pp. 11-24.

DUTRA, D. P. (2003). A formação pré-serviço e o currículo de Letras in: GIMENEZ, T. Ensinando e aprendendo Inglês na Universidade: Formação de professores em tempos de mudança. Londrina, PR: ABRAPUI

DUTRA, D. \& MELLO, H. (2004). A prática reflexiva na formação inicial e continuada de professores de Língua Inglesa in: VIEIRA-ABRAHÃO (org.) Prática de ensino de língua estrangeira: experiências e reflexões. Campinas, SP: Fontes Editora.

FARRELL, T. S. C. \& PARTICIA, L. P. C. (2005). Conceptions of Grammar Teaching: A case study of Teachers' Beliefs and Classroom Practices in: TESL-EJ, vol. 09, $\mathrm{n}^{\circ} 02$

FREIRE, M. M. \& LESSA, Â. B.C. (2003). Professores de inglês da rede pública: suas representações, seus repertórios e nossas interpretações in: BARBARA, L. e RAMOS, R. C. (orgs.) Reflexão e ações no ensino-aprendizagem de línguas. Campinas: Mercado de Letras.

FREUDENBERGER, F. \& ROTTAVA, L. (2004). A formação das crenças de ensinar de professores: a influência do curso de graduação in: ROTTAVA e LIMA (orgs.) Lingüística Aplicada: relacionando teoria e prática no ensino de línguas. Ijuí, RS: Ed. Unijuí.

GHIRARDI , J. G. (2003). A formação, a mudança e a identidade, os sentidos da mudança: crítica e docência frente aos discursos de transformação in: GIMENEZ, T. (org.) Ensinando e aprendendo Inglês na Universidade - Formação de professores em tempos de mudança. Londrina, PR: ABRAPUI.

GIL, G. (2005). Mapeando os estudos de formação de professores de línguas no Brasil in: FREIRE, ABRAHÃO e BARCELOS (orgs.) Lingüística Aplicada e Contemporaneidade. Campinas, SP: Pontes Editores.

GIL, G.; RAUBER, A. S.; CARAZZAI, M. R.; BERGSLEITHNER, J. (orgs.) (2005). Pesquisas qualitativas no ensino e aprendizagem de língua estrangeira: a sala de aula e o professor. Florianópolis, SC: UFSC.

GIMENEZ, T. (2005). Desafios contemporâneos na formação de professores de línguas: contribuições da Lingüística Aplicada in: FREIRE, ABRAHÃO e BARCELOS (orgs.) Lingüística Aplicada e Contemporaneidade. Campinas, SP: Pontes Editores. 
GIMENEZ, T. (2004). T. Tornando-se professores de Inglês: Experiências de formação inicial em um curso de Letras in: VIEIRA-ABRAHÃO, M. H. Prática de ensino de língua estrangeira: experiências e reflexões. Campinas, SP: Pontes Editores.

GIMENEZ, T.; ARRUDA, N. I. E LUVUZARI, L. H. (2004). Procedimentos reflexivos na formação de professores: uma análise de propostas recentes in: Intercâmbio, vol. XIII.

GIMENEZ, T. (2002). Trajetórias na formação de professores de línguas. Londrina, PR: Ed. UEL.

. (1994). Learners becoming teachers: an explanatory study of beliefs held by prospective and practicing EFL teachers in Brazil. Tese de Doutorado não publicada. Lancaster University.

HARKOT-DE-LA-TAILLE, E. (2003). A formação, a mudança e a identidade - a identidade em transformação in GIMENEZ, T. Ensinando e aprendendo Inglês na Universidade - Formação de professores em tempos de mudança. Londrina, PR: ABRAPUI.

JOHNSON, K. E. (1999). Understanding language teaching. Toronto: Heinle \& Heinle Publishers.

K. E. (1994). The emerging beliefs and instructional practices of preservice English as a second language teachers in: Teaching and teacher education. Vol. 10, $\mathrm{n}^{\circ}$ 4, pp. 439-452.

JORGE, M. L. S. (2003). O diálogo colaborativo e a reflexão crítica na formação de professores de Inglês in: GIMENEZ, T. (org.) Ensinando e aprendendo Inglês na Universidade - Formação de professores em tempos de mudança. Londrina, PR: ABRAPUI.

KLEIMAN, A. B. (2001). A formação do professor: perspectivas da Lingüística Aplicada. Campinas: Mercado de Letras.

KUDIESS, E. (2005). As crenças e os sistemas de crenças do professor de Inglês sobre o ensino e a aprendizagem da língua estrangeira no sul do Brasil: sistemas, origens e mudanças in: Linguagem \& Ensino vol. 8 n $^{\circ}$ 2, pp. 39-96.

LEFFA, V. (2005). O professor de línguas estrangeiras: do corpo mole ao corpo dócil in: FREIRE, VIEIRAABRAHÃO e BARCELOS (orgs.) Lingüística Aplicada e Contemporaneidade. Campinas, SP: Pontes Editores.

(org.). (2001). O professor de Línguas Estrangeiras: construindo a profissão. Pelotas, RS: Educat.

LIBERALI, F. MAGALHÃES, M. C. C. e SOUZA ROMERO, T. R. (2003). Autobiografia, diário e sessão reflexiva: atividades na formação crítico-reflexiva de professores in: CELANI (org.) Professores e formadores em mudança: relato de um processo de reflexão e transformação da prática docente. Campinas, SP: Mercado de Letras.

LIMA, S. S. (2005). Crenças de uma professora e alunos da quinta série e suas influências no processo de ensino-aprendizagem de Inglês na escola pública. Dissertação de Mestrado. UNESP/IBILCE - SP.

LORTIE, D.C. (1975). Schoolteacher: a sociological study. Chicago: Univ. of Chicago press.

MADEIRA, F. (2005a). Crenças de professores de Português sobre o papel da gramática no ensino de Língua Portuguesa in: Linguagem \& Ensino, vol. 8, $\mathrm{n}^{\circ}$ 2, pp. 17-35.

. (2005b). Alguns comentários sobre a pesquisa de crenças no contexto de aprendizagem de língua estrangeira in: Estudos Lingüísticos XXXIV, pp. 350-355.

MALATÉR, L. S. O. (1998). Teacher's beliefs on foreign language acquisition: a case study on classroom behaviors. Dissertação de mestrado. UFSC. 
LUZ - Discutindo o conceito de crenças na formação inicial do professor de línguas...

MASSAROLLO, J., FORTKAMP, M. B. M. (2002). Professores, alunos e suas crenças sobre o processo de ensino, desenvolvimento e avaliação da produção oral em LE. Anais em CD do III FILE. Pelotas: Scriptore.

MOITA LOPES, L. P. (2003). A nova ordem mundial, os parâmetros curriculares nacionais e o ensino de inglês no Brasil: a base intelectual para uma ação política in: BARBARA, L. e RAMOS, Rosinda C.G. (orgs.) Reflexão e ações no ensino-aprendizagem de línguas. Campinas: Mercado de Letras.

NÓVOA, A. (org.). (1997). Os professores e a sua formação. Lisboa: Publicações Dom Quixote.

OLIVEIRA E PAIVA, V. L. M. (2003). Avaliação das condições de oferto dos cursos de Letras in: GIMENEZ, T. (org.) Ensinando e aprendendo Inglês na Universidade: Formação de professores em tempos de mudança. Londrina, PR: ABRAPUI.

PAJARES, M. F. (1992). Teacher's beliefs and educational research: cleaning up a messy construct. Review of Educational Research, v. 62, pp. 307-332.

PERRENOUD, Ph. (2001). A prática reflexiva no ofício de professor: profissionalização e razão pedagógica. Porto Alegre: Artmed Editora.

PIMENTA, S.G. e GHEDIN, E. (orgs.). (2002). Professor reflexivo no Brasil: gênese e crítica de um conceito. São Paulo: Cortez.

PINHEIRO, L. F. C. (2003). O processo reflexivo e a tomada de consciência do professor multiplicador in: CELANI (org.) Professores e formadores em mudança: relato de um processo de reflexão $e$ transformação da prática docente. Campinas, SP: Mercado de Letras.

SCHÖN, D. A. (2000). Educando o profissional reflexivo: um novo design para o ensino e aprendizagem. Porto Alegre: Artmed Editora.

SILVA, V. L. T. (2004). Um olhar sobre as crenças de egressos de um curso de Letras - língua estrangeira sobre a fluência oral in: ROTTAVA e LIMA (orgs.) Lingüística Aplicada: relacionando teoria e prática no ensino de línguas. Ijuí, RS: Ed. Unijuí.

SOARES, O. (1952). Dicionário de Filosofia. Vol I: A-D. Rio de Janeiro: Instituto Nacional do Livro.

VECHETINI, LILIAN ROSE. (2005). Crenças sobre o ensino de vocabulário em língua estrangeira (Inglês) para alunos iniciantes. Dissertação de Mestrado. UNICAMP/IEL.

VIEIRA-ABRAHÃO, M. H. (2004). Crenças, pressupostos e conhecimentos de alunos-professores de língua estrangeira e sua formação inicial in: ABRAHÃO, M. H. V. (org.) Prática de ensino de língua estrangeira: experiências e reflexões. Campinas, SP: Pontes Editores.

XAVIER, R. P. e GIL, G. (2004). As práticas no curso de licenciatura em Letras-Inglês da Universidade Federal de Santa Catarina in: VIEIRA-ABRAHÃO, M. H. Prática de ensino de língua estrangeira: experiências e reflexões. Campinas, SP: Pontes Editores.

ZYNGIER, S. e LIBERALI, F. (2003). Reflexão crítica e o compromisso social na formação de professores in: GIMENEZ, T. (org.) Ensinando e aprendendo Inglês na Universidade - Formação de professores em tempos de mudança. Londrina, PR: ABRAPUI.

Recebido: 25/07/2006

Aceito: 12/12/2006 